\title{
Reseña bibliográfica: López, I. (2018). La república del fraude y sus crisis. Política y poder en tiempos de Roberto M. Ortiz y Ramón S. Castillo: Argentina, 1938-1943. Rosario: Prohistoria. 293 pp.
}

\author{
Palabras claves: Historia Argentina - Década del Treinta -Fraude - \\ Intervenciones Federales
}

Keywords: History of Argentina - The Thirties Decade - Electoral Fraud Federal Interventions

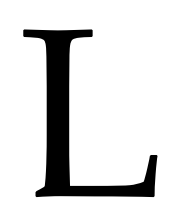

a obra de Ignacio López presenta un análisis pormenorizado y bien documentado de la vida política argentina bajo las presidencias de Roberto Ortiz y Ramón Castillo. La reconstrucción de las vicisitudes de esos años se lleva a cabo mediante la presentación y el abordaje crítico de los programas y proyectos de cada presidente, como así también de un completo análisis de las dinámicas partidarias del oficialismo y la oposición, las prácticas electorales y las sucesivas coyunturas políticas signadas por los acontecimientos políticos locales y el trasfondo de la Segunda Guerra Mundial que tiene lugar por entonces.

El libro es fruto de la tesis doctoral del autor, defendida en la Universidad Torcuato di Tella. Se estructura en ocho capítulos que abarcan el período 1938-1943, añadiéndose al final una serie de tablas, documentos y mapas de gran utilidad analítica. Para la denominación de los capítulos se recurre metafóricamente a los "tempos" musicales: son aquellas indicaciones colocadas en el primer pentagrama de una partitura que señalan al intérprete la velocidad de la ejecución musical. En este caso, la aplicación de estas referencias en su denominación original en italiano refleja con genialidad el ritmo que van tomando los acontecimientos políticos en las sucesivas coyunturas analizadas.

El primer capítulo, Moderato, abarca de febrero de 1938 a abril de 1939. Aborda la candidatura de Ortiz en 1937, la campaña y su triunfo en las elecciones, repasando además su cursus honorum previo. Focaliza luego en su construcción de poder como presidente -maniobrando exitosamente frente al influjo de Justo y de los otros actores de la Concordancia- y repasa el plexo de valores de su ideario, como así también las primeras iniciativas legislativas en pos de la reimplantación paulatina de garantías electorales. La consolidación de su capital político propio se da tanto en el frente militar como en el plano partidario, en vistas a neutralizar el predominio conservador en las 
provincias. En este marco, se estudian las elecciones del período 1938-1939 y la intervención federal a San Juan en 1938, evidenciando las disputas puertas adentro de la coalición oficial y las tensiones con los gobernadores opositores.

Continúa luego el "tempo" Andante vivace (abril de 1939 a febrero de 1940). Se trata del momento de mayor estabilidad del proyecto político de Ortiz, reflejado en su buena relación con las Fuerzas Armadas y en las acciones de "disciplinamiento" del fraude. Se analizan aquí las intervenciones federales en Santiago del Estero, San Juan y Catamarca. Por otro lado, se reconstruye el pensamiento presidencial a través de la documentación oficial y por medio de cartas, telegramas y noticias de la prensa periódica.

El tercer apartado, Allegro -marzo a junio de 1940- ratifica la solidez de la posición presidencial y nuevos hitos en su proyecto de regeneración democrática. Se analizan los discursos de sesiones legislativas y las acciones parlamentarias en política exterior. Después se estudia la intervención a la provincia de Buenos Aires de marzo de 1940, luego de la realización de elecciones fraudulentas con las que el PDN buscó mantener la gobernación. Tal intervención promovió el acercamiento de Ortiz a la oposición (la UCR y el Partido Socialista) por su política de limpieza electoral y, como contracara, el enfrentamiento con los legisladores y ministros del PDN. Sobre el final se pone en evidencia el apoyo de la prensa, la opinión pública y de gobernadores no oficialistas a la acción de Ortiz, remitiendo para ello al análisis de distintas situaciones provinciales: Salta, Jujuy, Santa Fe, Mendoza, Entre Ríos y Córdoba.

El cuarto capítulo -Presto agitato- evidencia las tormentas que se ciernen sobre el proyecto de Ortiz, una vez que este se ve aquejado por una ceguera que se irá agravando paulatinamente, y cede en julio de 1940 el mando -en forma previsional- al vicepresidente Castillo. El autor reconstruye aquí la trayectoria previa del vicepresidente, su arribo "tardío" a la política y su ascenso dentro de las filas del PDN. Luego, señala cómo el tablero de piezas se va reacomodando a favor de Castillo a medida que avanza la enfermedad del presidente. El puntapié inicial es el "Escándalo del Palomar", al que sigue el fortalecimiento de Castillo con el nombramiento de su propio gabinete y el realineamiento de las provincias gobernadas por la coalición oficialista a su favor. Se abordan aquí las elecciones para gobernador de Mendoza y Santa Fe, como así también elecciones de senadores hechas en varias provincias, reflejando todo ello el "guiño" favorable al fraude del oficialismo demócrata y el rechazo de los opositores, la prensa y el parlamento al retorno del fraude.

El siguiente apartado, Vivaccisimo, abarca de febrero a mayo de 1941. Focaliza en las reacciones de los actores políticos y el Congreso frente a la reactivación del fraude, incluyendo la voz lejana de Ortiz que todavía se pronuncia. Se examina cómo su enfermedad toma estado parlamentario -entre otras cosas se crea una comisión de estudio de su caso y un proyecto de ley de acefalía- y cómo su retorno al poder se vuelve imposible merced al avance de su enfermedad y la amenaza demócrata de iniciarle un proceso por "inhabilidad" para el cargo. Mediante las voces de la prensa, los partidos y la tribuna parlamentaria se pone en evidencia el nivel de gravedad institucional que 
alcanzó la situación de Ortiz y la apertura cada vez más clara de una sucesión favorable al PDN.

El sexto capítulo es Adagio y va desde mayo de 1941 a junio de 1942. López reconstruye aquí las ideas políticas de Castillo y las implicancias de su posición de pasividad como titular del Ejecutivo frente al fraude, camino a su ascensión con "plenos poderes" al cargo. Se muestra la construcción de poder político propio del vicepresidente tanto en el plano militar como frente a los espacios de poder de la oposición, esto último mediante la normalización de las provincias intervenidas por Ortiz y la reorientación de las alianzas políticas provinciales en favor del PDN. Se realiza un análisis detallado de las situaciones políticas en provincias como Catamarca, San Juan, Buenos Aires y Jujuy, evidenciando ello el modus operandi respecto de las elecciones y nuevas intervenciones sobre distritos controlados por la oposición. La última fase -de marzo a junio de 1942- remite a la gestación de una coyuntura favorable a la restauración definitiva de la "república del fraude", camino que se allana claramente con las muertes de Alvear en marzo y la renuncia definitiva y muerte de Ortiz, en junio de 1942.

El penúltimo capítulo, Grave, va de junio de 1942 a enero de 1943. Refleja cómo la muerte de Ortiz abre las disputas en torno a la contienda por la candidatura oficial concordancista en vistas a la sucesión de 1943. Reconstruye la "guerra fría" entre Castillo y Justo hasta el fallecimiento de este último en enero de 1943, la construcción de vínculos dentro del Ejército y la legitimación de su autoridad que lleva adelante el presidente frente a los actores institucionales y políticos para reafirmar su preponderancia en la coalición de gobierno y su gravitación sobre provincias intervenidas, como Corrientes y Tucumán.

El último apartado -Finale con moto- abarca de febrero a junio de 1943. La muerte de Justo fortalece aún más a Castillo y lo habilita a definir a su sucesor. Advierte certeramente López que "entre la providencia y la estrategia", Castillo logró sortear todos los inconvenientes y pudo imponer a su sucesor: el empresario azucarero Robustiano Patrón Costas. Se pone el foco luego en el avance de esta candidatura, la trayectoria e ideas previas del candidato, la neutralización de la oposición del PDN bonaerense a la misma, los apoyos recibidos e igualmente las críticas por la "mala fama" del personaje. Asimismo, se plantea la cuestión de la candidatura a la vicepresidencia, para la cual se prefiguraban propuestas distintas de los partidos concordancistas, que se proclamarían el 4 de junio, día en el que finalmente el golpe militar. Se analiza a continuación la gestación de la "Unión Democrática" como actor aglutinante del espectro opositor, en el marco de los clivajes políticos e ideológicos de la época. La última parte, "El final anunciado", aborda los prolegómenos del golpe del 43, la situación interna de las Fuerzas Armadas y la cuestión del uso partidario de estas que pretendía hacer Castillo para imponer a su delfín. Reseña también la constitución y acciones del GOU, los movimientos de los actores políticos y militares y los hechos que conducen a la madrugada del 4 de junio. 
La obra presenta un profundo análisis de las figuras presidenciales mencionadas y de las acciones políticas de ambos mandatarios en el marco de programas, pertenencias partidarias e ideologías distintas, que signaron la etapa final de la "república del fraude" de los años treinta. En el fondo, contribuye a reconsiderar los debates sobre la democracia de esos años y el sustrato de condiciones que darán lugar a la irrupción de las Fuerzas Armadas en la escena política en 1943. Habilita así una mirada de mediano plazo en torno a los debates sobre la Ley Sáenz Peña y el derrotero democrático, en el marco de las tradiciones y la cultura política argentinas.

Además de un completo estudio de la historiografía sobre los años treinta, el texto evidencia un amplio dominio de referencias bibliográficas que permiten al lector la profundización de temas puntuales, por lo que se convierte en un estudio altamente sugerente y enriquecedor para quienes se inmiscuyen en los temas de historia política e institucional argentina del siglo XX en general y de los años treinta en particular.

Andrés Abraham

INCIHUSA-CONICET

Universidad Nacional de Cuyo, Argentina

andresabraham04@gmail.com

Para citar esta reseña:

Abraham, Andrés (2019). “Reseña bibliográfica: López, I. (2018). La república del fraude y sus crisis. Política y poder en tiempos de Roberto M. Ortiz y Ramón S. Castillo: Argentina, 1938-1943. Rosario: Prohistoria. 293 pp.". Anuario de la Escuela de Historia Virtual, 16, pp. 176-179. 